\title{
Advances in critical care management of patients undergoing cardiac surgery
}

\author{
Anders Aneman ${ }^{1 *}$ D, Nicholas Brechot ${ }^{2}$, Daniel Brodie ${ }^{3}$, Frances Colreavy ${ }^{4}$, John Fraser ${ }^{5}$, Charles Gomersall $^{6}$, \\ Peter McCanny ${ }^{7}$, Peter Hasse Moller-Sorensen ${ }^{8}$, Jukka Takala ${ }^{9}$, Kamen Valchanov $^{10}$ and Michael Vallely ${ }^{11}$
}

(0) 2018 Springer-Verlag GmbH Germany, part of Springer Nature and ESICM

\begin{abstract}
Cardiac surgery has been evolving to include minimally invasive, hybrid and transcatheter techniques. Increasing patient age and medical complexity means that critical care management needs to adapt and evolve. Recent advances have occurred in several areas, including ventilation, haemodynamics and mechanical circulatory support, bleeding and coagulation, acute kidney injury, and neurological management. This narrative review describes standard care, recent advances, and future areas of research in the critical care management of patients undergoing cardiac surgery.
\end{abstract}

Keywords: Cardiac surgery, Intensive care

This is an invited summary of recent advances and areas of future research in the management of the adult cardiac surgical patient in the intensive care unit. Areas have been selected on the basis of clinical significance, change in practice, recent new evidence or ongoing controversy.

\section{Trends in cardiac surgery}

Minimally invasive, hybrid and transcatheter techniques coupled with the increasing age and medical complexity of the patients has mandated a different approach to cardiac surgical patients. The recent concept of "The Heart Team" has dramatically changed the way patients are managed. This includes referral to centres rather than individual surgeons, assessment in multidisciplinary clinics, procedures performed by two or more proceduralists and postoperative care in high-end dedicated facilities.

Because of the ageing population and increased referral for procedures based on the benefits (perceived or otherwise) of transcatheter and minimally invasive techniques, the number of cardiac surgical patients over 80 years old has increased up to 24 -fold over the last two decades [1,

\footnotetext{
*Correspondence: anders.aneman@health.nsw.gov.au

${ }^{1}$ Intensive Care Unit, Liverpool Hospital, Southwestern Sydney Local Health District, Locked Bag 7103, Liverpool BC, NSW 1871, Australia Full author information is available at the end of the article
}

2]. A flow-on effect of increased transcatheter procedures has been an increased referral for more complex valvular surgical procedures [2].

Risk scores, such as EuroSCORE and the STS risk score, have been popular and widely used in cardiac surgery over the past two decades. However, elderly and high-risk patients have not featured heavily in the datasets, and the often complex nature of the patients has mandated a different approach [3]. Assessment by multi-disciplinary teams and a focus on frailty has allowed a more accurate evaluation of this patient population. The immediate procedural risks can be assessed, as can the potential longterm benefits including quality of life and reduced hospital readmissions, of complex and expensive procedures [4].

Coronary artery surgery remains the most common adult cardiac surgical procedure performed worldwide, with aortic valve surgery being the most common valve procedure. Elderly patients in particular may benefit from advanced techniques such as anaortic off-pump coronary surgery where surgical revascularisation is performed without a heart-lung machine and without manipulating the aorta $[5,6]$. This avoids end-organ injury caused by emboli that may be generated by the cardiopulmonary bypass $(\mathrm{CPB})$ circuit and aortic cross-clamping. An example of a multidisciplinary approach to complex

\section{伨


problems is the use of hybrid techniques where transcatheter technology is used in conjunction with open surgery (Fig. 1) [7].

Minimally invasive cardiac surgery is becoming more common [8]. Elderly patients may benefit from this approach with less tissue trauma and shorter recovery times. However, the need for peripheral (femoral) cannulation for bypass may increase the risk of retrograde embolisation of atheromatous plaque and this must be considered when deciding the appropriate surgical approach. The postoperative management of patients who have minimally invasive surgery is different to surgery via a sternotomy. Patients are often "fast-tracked" and admitted to the intensive care, intermediate or stepdown unit extubated. In the event of bleeding or cardiac tamponade, re-entry can be more difficult and may require a de novo sternotomy in the intensive care unit.

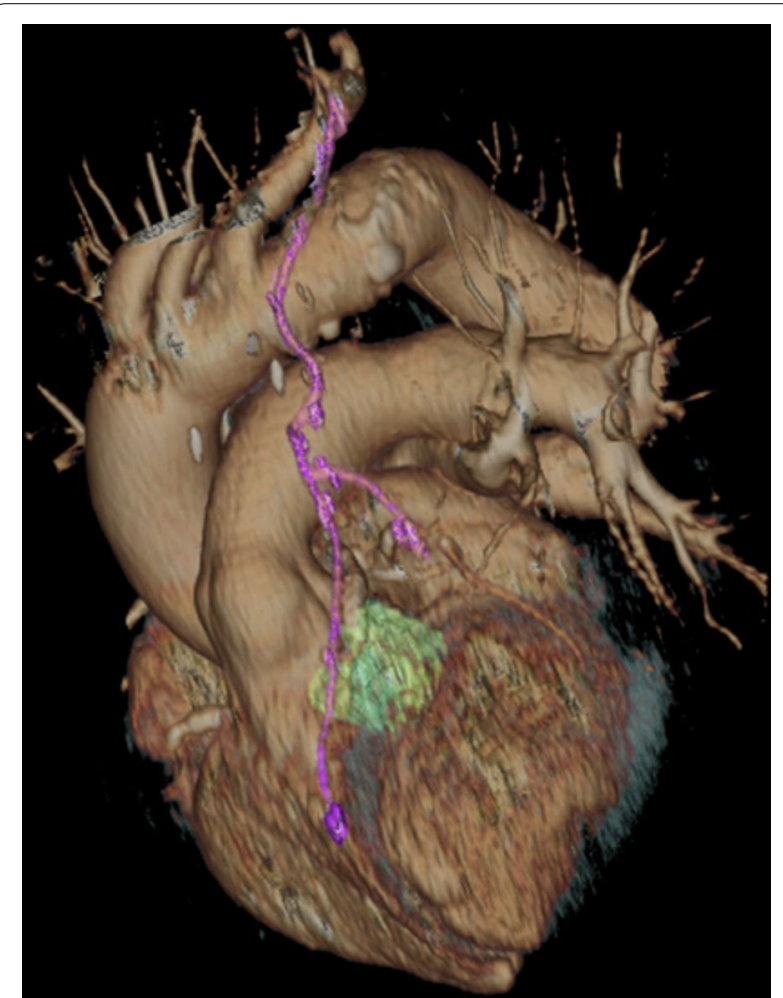

Fig. 1 An elderly patient with severe peripheral vascular disease, aortic stenosis and complex unstentable coronary artery disease underwent a combined multi-vessel off-pump CABG and transcatheter AVR in a single procedure. 3D reconstruction of the post-procedure result from a combined transcatheter aortic valve implantation (green) and multi-vessel off-pump coronary artery bypass grafting (purple) is shown. This required multiple proceduralists with complementary skill-sets to achieve an excellent result in this elderly and high-risk patient

\section{Background and recent advances Respiratory considerations}

Pulmonary dysfunction occurs in $10-25 \%$ of cardiac surgical patients and is a major contributor to early and late morbidity [9]. It has a multifactorial origin including: coexisting preoperative pulmonary disease; use of $\mathrm{CPB}$ with minimal to absent ventilation and inflammatory injury; intraoperative lung manipulation; intrathoracic bleeding and blood product administration; and mechanical and pain factors related to surgical incision. Atelectasis and pleural effusions occur in almost all patients.

Lung-protective ventilation and alveolar recruitment manoeuvres, which may commence intraoperatively, are suggested for optimisation of postoperative gas exchange and reduction of ventilator-associated lung injury [10].

\section{Recent advances}

Adaptive support ventilation and automated weaning protocols for cardiac patients may result in faster weaning and extubation when compared to traditional ventilatory modes in fast-track surgical patients [11]. While the clinical significance of shortened weaning times may be questioned, no worse outcomes with closed loop weaning have been demonstrated.

For extubated patients, a randomised controlled trial (RCT) of the routine use of high-flow nasal oxygen failed to improve the oxygen saturation to inspired fraction of oxygen ratio compared to usual therapy [12]. A recent RCT demonstrated non-inferiority of high-flow nasal oxygen compared to non-invasive ventilation (NIV) when used prophylactically in cardiothoracic patients at high risk of reintubation or as rescue therapy in postextubation respiratory failure [13]. Although commonly applied in many centres, there is only sparse high-quality evidence to support the use of NIV following cardiac surgery.

\section{Haemodynamic considerations}

Cardiac surgery results in a moderate hypermetabolic state that imposes a risk for perfusion supply/metabolic demand mismatch, especially in the presence of cardiac dysfunction and limited cardiovascular reserve. Postoperative cardiovascular support aims to minimise any systematic or regional supply/demand mismatch.

An increase in whole-body oxygen consumption $\left(\mathrm{VO}_{2}\right)$ by $10-20 \%$ occurs on the first postoperative day and is sustained for at least $24-48 \mathrm{~h}$, particularly as mechanical ventilator support is weaned and the patient mobilised, and may be further increased in the setting of pain, anxiety or delirium. Hepatosplanchnic oxygen extraction [14] and renal $\mathrm{VO}_{2}$ increase in the early postoperative period (the latter up to 50\%) [15]. This is not matched by corresponding increases in regional blood flow, as the proportion of cardiac output $(\mathrm{CO})$ remains the same. The splanchnic 
perfusion may be further compromised due to increased preload, venous congestion and redistribution of blood flow towards the periphery associated with vasodilatation. Insufficient $\mathrm{CO}$ and high systemic oxygen extraction in the early postoperative period has been associated with adverse outcomes [16].

The focus of intensive care management after cardiac surgery is to maintain adequate organ perfusion. While multiple devices are available to monitor $\mathrm{CO}$, the approach to evaluating organ perfusion is more complex.

A postoperative low-CO syndrome affects up to $20 \%$ of cardiac surgical patients [9]. Catecholamines and phosphodiesterase inhibitors are commonly used to support $\mathrm{CO}$, although no RCTs have demonstrated their benefit and some meta-analyses and observational data suggest that they might adversely affect survival [17].

Up to $25 \%$ of patients develop a vasoplegic syndrome with hypotension [mean arterial pressure $(\mathrm{MAP})<60 \mathrm{mmHg}$ ] and high cardiac index $\left(>3.5 \mathrm{~L} / \mathrm{min} / \mathrm{m}^{2}\right)$ that require escalating doses of vasopressors or occasionally multiple vasopressor agents [9]. Conversely, vasodilators may be needed to control hypertension, especially in the context of aortic valve replacements and procedures on the aorta.

\section{Recent advances}

Haemodynamic management largely relies on the extrapolation of $\mathrm{CO}$ to reflect regional perfusion, supported by laboratory investigations of organ function. Several relatively small, mostly single-centre studies and a metaanalysis have suggested improved outcomes from interventions goal-directed therapy aimed at preventing low $\mathrm{CO}$ or low mixed venous oxygen saturation. High-quality evidence for such interventions is lacking [18].

The optimal assessment of fluid responsiveness remains a controversial area in postoperative cardiac care. While reliance on static filling pressures is rare in modern practice, dynamic measures such as stroke volume variation and pulse pressure variation are confounded by right ventricular dysfunction, early extubation and spontaneous breathing.

Most evidence regarding intravenous fluids has been gathered outside the cardiac surgical population and considerable variability exist in clinical practice without consensus guidelines. The trend in fluid administration in cardiothoracic patients includes restrictive intra-operative and postoperative fluid administration [19].

Three recent large RCTs (LEVO-CTS [20], LICORN [21], CHEETAH [22]) did not demonstrate any benefit of perioperative levosimendan, and a meta-analysis of five low risk of bias trials including 1910 patients showed no association between levosimendan use and mortality, acute kidney injury (AKI), need for renal replacement therapy, myocardial infarction or ventricular arrhythmias, but an association with a higher incidence of supraventricular arrhythmias [23].

Methylene blue has been suggested to treat postoperative vasoplegic syndrome. The optimal timing, dose and patient selection remains unknown as most evidence to support its use is based on small case series. It is still considered a rescue therapy [24].

Remote ischaemic preconditioning stipulates that producing remote ischaemia (by blood pressure cuff applied to the arm) prior to surgery would induce protective mechanisms in the myocardium and reduce postoperative morbidity and mortality. While the data for this intervention are difficult to interpret, the Cochrane review in 2017 [25] demonstrated that remote ischaemic preconditioning has no treatment effect on mortality, non-fatal myocardial infarction or stroke following coronary artery bypass surgery.

\section{Mechanical circulatory support}

Mechanical circulatory support (MCS) is a broad term encompassing a range of devices used for short- and long-term cardiovascular support (Table 1).

Short-term MCS is intended as a temporising measure to rescue patients with acute decompensated heart failure, cardiogenic shock including postcardiotomy cardiogenic shock, refractory ventricular arrhythmias, massive pulmonary embolism or pulmonary hypertensive crisis. It may also be employed prophylactically prior to invasive cardiac procedures in patients at high risk for cardiovascular decompensation intra-operatively. A graphical representation of some common short-term MCS devices is shown in Fig. 2.

The goal with short-term MCS is to bridge the patient either to recovery, surgery, durable device, or to decision if there is prognostic uncertainty. There is a paucity of evidence for the selection and timing of MCS in patients with cardiogenic shock. Such decisions should be undertaken by experienced multi-disciplinary teams [26]. The aetiology of cardiogenic shock largely determines the prognosis, regardless of the MCS device chosen, with postcardiotomy cardiogenic shock typically having the worst prognosis [27].

\section{Intra-aortic balloon pump (IABP)}

The IABP is the most commonly used form of MCS as it is easy to deploy and the least expensive. The use of IABP has recently been questioned, particularly in patients with cardiogenic shock after acute myocardial infarction, since the IABP-SHOCK II trial failed to show a benefit on 30-day mortality in this setting [28], resulting in a downgrading of the recommendations for its use both in Europe and in the United States [26]. 
Table 1 Mechanical circulatory support devices

\begin{tabular}{|c|c|c|c|c|c|c|c|c|}
\hline & IABP & Percutaneous & VAD & VA-ECMO & Surgical VAD & & & \\
\hline & & Impella & $\begin{array}{l}\text { Tandem- } \\
\text { Heart }\end{array}$ & & Centrimag & Abiomed & HeartMate II & HVAD \\
\hline Mechanism & $\begin{array}{l}\text { Counterpulsa- } \\
\text { tion }\end{array}$ & $\begin{array}{l}\text { Axial continu- } \\
\text { ous flow }\end{array}$ & $\begin{array}{l}\text { Centrifugal } \\
\text { continuous } \\
\text { flow }\end{array}$ & $\begin{array}{l}\text { Centrifugal } \\
\text { continuous } \\
\text { flow }\end{array}$ & $\begin{array}{l}\text { Centrifugal } \\
\text { continuous } \\
\text { flow }\end{array}$ & $\begin{array}{l}\text { Pneumatic } \\
\text { pulsatile } \\
\text { flow }\end{array}$ & $\begin{array}{l}\text { Rotary } \\
\text { continuous } \\
\text { flow }\end{array}$ & $\begin{array}{l}\text { Centrifugal con- } \\
\text { tinuous flow }\end{array}$ \\
\hline Support & LV support & $\begin{array}{l}\text { LVAD } \\
\text { RVAD }\end{array}$ & $\begin{array}{l}\text { LVAD } \\
\text { RVAD } \\
\text { BiVAD }\end{array}$ & $\begin{array}{l}\text { LV/RV support, } \\
\text { Oxygenation }\end{array}$ & $\begin{array}{l}\text { LVAD } \\
\text { RVAD } \\
\text { BiVAD }\end{array}$ & $\begin{array}{l}\text { LVAD } \\
\text { RVAD } \\
\text { BiVAD }\end{array}$ & LVAD & VAD \\
\hline Effect on LV/LA & $\downarrow L V$ afterload & $\begin{array}{l}\text { Unloads } \\
\text { LV/RV }\end{array}$ & $\begin{array}{l}\text { Unloads } \\
\text { LA }\end{array}$ & $\begin{array}{l}\uparrow L V \\
\text { afterload }\end{array}$ & $\begin{array}{l}\text { Unloads } \\
\text { LV }\end{array}$ & $\begin{array}{l}\text { Directly } \\
\text { Unloads } \\
\text { LV }\end{array}$ & $\begin{array}{l}\text { Directly } \\
\text { Unloads } \\
\text { LV }\end{array}$ & $\begin{array}{l}\text { Directly } \\
\text { Unloads } \\
\text { LV }\end{array}$ \\
\hline $\begin{array}{l}\text { Device-specific } \\
\text { potential } \\
\text { issues }\end{array}$ & $\begin{array}{l}\text { Air emboli } \\
\text { Malposition } \\
\text { Aortic injury } \\
\text { Mesenteric } \\
\text { thrombosis } \\
\downarrow \text { platelets }\end{array}$ & $\begin{array}{l}\text { Haemolysis, } \\
\text { Pump migra- } \\
\text { tion } \\
\text { AV injury } \\
\text { Tamponade } \\
\text { Ventricular } \\
\text { arrhythmias }\end{array}$ & $\begin{array}{l}\text { Cannula } \\
\text { migration, } \\
\text { Tamponade } \\
\text { Emboli } \\
\text { Inter-atrial } \\
\text { shunt }\end{array}$ & $\begin{array}{l}\text { Circuit clotting } \\
\text { LV dilatation } \\
\text { Differential } \\
\text { hypoxia } \\
\text { (peripheral } \\
\text { VA-ECMO) }\end{array}$ & $\begin{array}{l}\text { Blood or air } \\
\text { emboli }\end{array}$ & $\begin{array}{l}\text { Limited mobil- } \\
\text { ity } \\
\text { Bleeding, } \\
\text { sepsis }\end{array}$ & $\begin{array}{l}\text { Bleeding, } \\
\text { Sepsis, } \\
\text { RV failure }\end{array}$ & $\begin{array}{l}\text { Bleeding, sepsis, } \\
\text { RV failure }\end{array}$ \\
\hline $\begin{array}{l}\text { Device-specific } \\
\text { benefits }\end{array}$ & $\begin{array}{c}\text { Easy, rapid } \\
\text { insertion }\end{array}$ & $\begin{array}{l}\text { Multiple } \\
\text { platforms }\end{array}$ & $\begin{array}{l}\text { Haemo- } \\
\text { dynamic } \\
\text { stability }\end{array}$ & $\begin{array}{l}\text { Rapid, bedside } \\
\text { insertion } \\
\text { Oxygenation }\end{array}$ & $\begin{array}{l}\text { Extensive } \\
\text { experience } \\
\text { May add oxy- } \\
\quad \text { genation }\end{array}$ & $\begin{array}{l}\text { Easy to use } \\
\text { Independent } \\
\text { of cardiac } \\
\text { rhythm }\end{array}$ & $\begin{array}{l}\text { Easy insertion } \\
\text { Small size }\end{array}$ & $\begin{array}{l}\text { Thoracic inser- } \\
\text { tion } \\
\text { Small size }\end{array}$ \\
\hline
\end{tabular}

$I A B P$ intra-aortic balloon pump, VAD ventricular assist device, VA-ECMO venoarterial extracorporeal membrane oxygenation, $H V A D$ Heartware ventricular assist device, $L V$ left ventricle, $L V A D$ left ventricular assist device, $R V A D$ right ventricular assist device, BiVAD biventricular assist device, $L A$ left atrium, $A V$ aortic valve

\section{Percutaneous ventricular assist devices}

The Impella and the TandemHeart are shorter-term MCS devices, which may be referred to as percuataneous ventricular assist devices (VADs), that in the typical configuration provide LV decompression by draining the left ventricle and left atrium, respectively, with arterial reinfusion. These devices are more expensive than ECMO, may not provide sufficient LV support, and do not provide gas exchange support. Nonetheless, their use appears to be increasing [29], with some guidelines explicitly favouring percutaneous VADs or ECMO over the IABP [30]. Common complications of the percutaneous VADs as well as venoarterial ECMO include limb ischemia, compartment syndrome, pseudoaneurysm, bleeding, thrombocytopenia, vascular injury, infection, thromboembolic events and haemolysis.

\section{Extracorporeal membrane oxygenation (ECMO)}

ECMO is a form of short-term MCS, which can provide either partial or full circulatory support through peripheral or central venoarterial cannulation [31]. The major advantages of ECMO are the provision of gas exchange support in addition to circulatory support, and rapid initiation, even at the bedside through peripheral cannulation. One major disadvantage of peripheral venoarterial ECMO is the increased left ventricular afterload, which may lead to LV distension, necessitating venting manoeuvres. Venoarterial ECMO is useful as a bridge to recovery, longer-term mechanical support or heart transplantation. ECMO is the MCS modality of choice for bridging patients with pulmonary hypertensive crisis [32] and the most straightforward short-term MCS approach to biventricular failure. The use of venoarterial ECMO has increased dramatically in recent years [33], particularly after the IABP-SHOCK II trial [34].

\section{Surgical ventricular assist devices}

Short-term surgical VADs may be implanted to support the left ventricle, the right ventricle or both. The CentriMag and Abiomed (Impella 5.0) VADs provide more stable short- and medium-term support. Long-term MCS is provided via a durable VAD, primarily the HeartMate II and III and the HeartWare HVAD, which are principally used either as a bridge to heart transplantation or as destination therapy [35], with the HeartMate III emerging as the next generation device.

\section{Recent advances}

Refinement of technology and expertise in MCS use and general aspects of care such as nutrition, mobilisation, asepsis, and psychological support have evolved.

The Impella RP (Fig. 2) has offered a viable option for patients with isolated right ventricular failure or biventricular failure where the left ventricle is supported by a long-term MCS device [36]. 


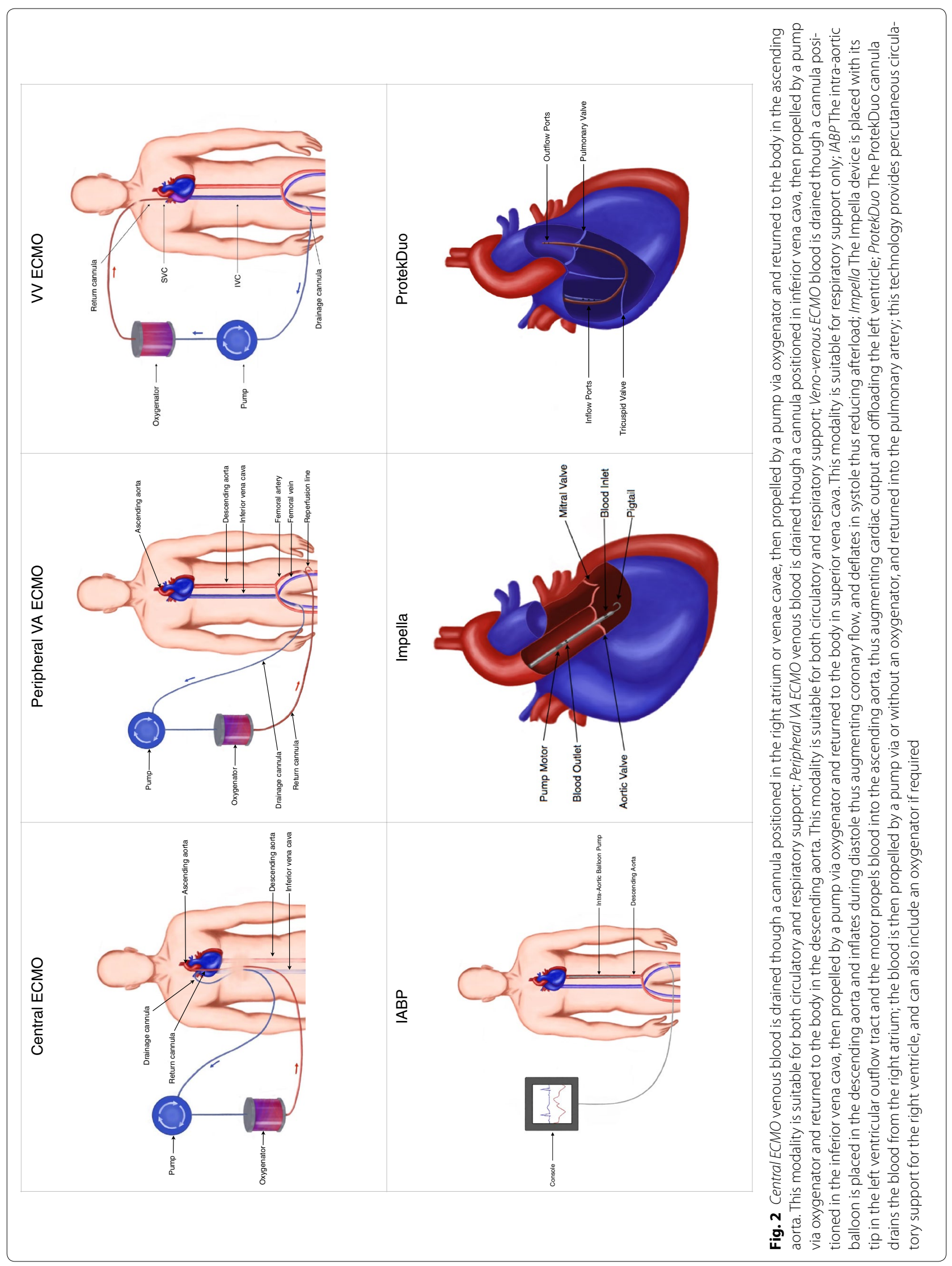


The ProtekDuo [37] is a new device for right ventricular support that has evolved from the TandemHeart technology. It has been used to support the right ventricle in patients with durable LVAD. In this setting, it supports marginal candidates and patients with unexpected perioperative right ventricular failure. Additionally, it has the option for oxygenation when required.

\section{Echocardiography}

Immediate $24 / 7$ access to echocardiography is key to managing the haemodynamic lability that is common following cardiac surgery. Transoesophageal echocardiography (TOE) is essential for diagnosing the cause of haemodynamic instability in ventilated patients post cardiac surgery. A TOE study may support a diagnosis of LV failure, hypovolaemia and myocardial ischaemia or identify cardiac surgical complications such as tamponade, dynamic LV outflow tract obstruction secondary to systolic anterior mitral valve leaflet motion, or acute RV failure. Even with harmonic imaging enhancement, transthoracic echocardiography (TTE) is often inadequate in patients immediately following cardiac surgery and has most utility following cardiac surgery when patients have been extubated and chest drains removed [38]. Lung ultrasound performed at the same time as TTE adds significant diagnostic information including identifying pulmonary oedema, pleural effusion, consolidation and pneumothorax.

\section{Recent advances}

Miniaturised disposable TOE probes have made continuous (up to $72 \mathrm{~h}$ ) monitoring available. Half the size of a standard probe, mTOE monoplane and colour flow imaging facilitates haemodynamic management in haemodynamically unstable patients postcardiac surgery [39]. The commonest interventions included changes in vasoactive medications in $45 \%$ and administration of additional fluids in $41 \%$ of patients. An mTOE-guided venoarterial ECMO weaning protocol has been used to predict the ability to wean venoarterial ECMO [40].

A frequent indication for echocardiography after cardiac surgery is assessment of ventricular function as reduced compliance and myocardial dysfunction are common. Three-dimensional (3D) TOE overcomes some of the problems of two-dimensional (2D) by capturing a pyramidal dataset enabling multiplanar reconstruction and more accurate LV volume assessment. Preliminary studies have demonstrated utility of 3D TOE in measuring $\mathrm{LV}$ and RV ejection fraction following cardiac surgery [41]. More recently, measurement of myocardial strain, using speckle-tracking echocardiography, supported earlier detection of myocardial dysfunction [42]. A reduction in intraoperative LV global longitudinal strain is an independent predictor of early postoperative dysfunction in patients undergoing cardiac surgery and is associated with longer hospitalisations in patients undergoing surgical aortic valve replacement for stenosis [41]. A reduction in global RV longitudinal strain is associated with RV failure following insertion of a LVAD [43]. These techniques to help with perioperative haemodynamic assessment following cardiac surgery hold significant potential.

\section{Haemostasis and transfusion of blood products}

The coagulopathy occurring with $\mathrm{CPB}$ is well described and postoperative bleeding is common. Excessive bleeding due to coagulopathy occurs in up to $10 \%$ of postoperative cases and is associated with worse outcome [44]. Traditional assessments of coagulation have limited ability to predict perioperative bleeding with a turnaround time of up to $1 \mathrm{~h}$. Viscoelastic testing using thromboelastography (TEG) and rotational thromboelastometry (ROTEM) have the advantage of providing insight into the physiologic activity of clotting factors, platelet function, and both fibrinogen and plasminogen activity with a rapid turnaround time.

Hypofibrinogenaemia $(<100 \mathrm{mg} / \mathrm{dL})$ is associated with increased bleeding and RBC use. Most transfusion algorithms suggest a trigger of $<150 \mathrm{mg} / \mathrm{dL}$ [45]. Options for replacement include FFP, cryoprecipitate, and fibrinogen concentrate. Replacement using fibrinogen concentrate, although a potentially attractive option, is not supported by current evidence [46] and its use is not currently approved in all countries.

Many patients undergoing coronary artery bypass surgery have received preoperative antiplatelet agents. In a recent RCT of coronary artery bypass surgery patients [47], aspirin was not associated with increased bleeding. Aspirin is usually continued preoperatively and, in the absence of major bleeding, should be commenced in the early postoperative phase.

The commonly used $\mathrm{P} 2 \mathrm{Y}_{12}$ platelet inhibitors (including clopidogrel, prasugrel, and ticagrelor) all increase the risk of cardiac surgery-related bleeding, with prasugrel associated with the highest perioperative bleeding rate [48]. Timing of cessation of these agents depends on the surgical urgency, balancing the risk for thrombosis versus the risk for bleeding: for elective cardiac surgical procedures, it is recommended that clopidogrel and ticagrelor should be stopped 5 days prior and prasugrel should be stopped 7 days prior owing to its prolonged action [49]. In high risk patients for whom cessation of dual antiplatelet therapy (DAPT) is deemed unsafe, $\mathrm{P}^{2} \mathrm{Y}_{12}$ inhibitors may be switched to an alternate antiplatelet agent with a shorter half-life (e.g. G2b-3a inhibitor tirofiban). In the absence of significant perioperative bleeding, DAPT should be resumed as soon as possible following surgery [49]. 


\section{Recent advances}

The use of TEG and ROTEM has been a key focus of research in the management of cardiac surgery-related bleeding and treatment algorithms incorporating these devices have shown reduction in blood product use, reduced incidence of re-exploration for postoperative bleeding, decrease in hospital cost, and reduction in offlabel use of recombinant activated factor VII (rFVII) as rescue therapy [45].

Observational data have previously described the adverse outcomes associated with red blood cell (RBC) and blood component transfusions in cardiac surgery patients. The optimal nadir for RBC transfusion has been debated, largely driven by data linking perioperative anaemia to worse outcome [50]. Three recent RCTs have compared 'restrictive' versus 'liberal' RBC transfusion targets in cardiac surgery. In both the TRACS [51] and TITRe 2 [52] trials, there was no difference in early mortality or morbidity, with use of a restrictive strategy, and RBC use was significantly reduced. However, in the restrictive group of the TITRe2 trial, there was an increase in the secondary outcome of 90-day mortality. The mechanism of this unexpected delayed mortality difference is unclear. The TRICS 3 trial [53] addressed the important question of RBC transfusion threshold in higher risk patients (based on EUROscore $\geq 6$ ), revealing no difference in the primary outcome of all-cause mortality or secondary outcomes of morbidity between transfusion targets. The recent INFORM and TRANSFUSE trials, both including cardiac surgical patients, found no difference in mortality when older versus fresher blood was used for transfusion $[54,55]$.

Use of factor concentrates including prothrombin complex concentrate is increasing, and has the advantages of lower volume load, rapid reconstitution and administration and a lower viral transmission risk, compared to FFP. It has been incorporated into point-of-care bleeding algorithms, and in a recent observational study was associated with reduced bleeding and less RBC transfusion than FFP [56]. The rFVIIa is a potent and effective haemostatic agent in post-CPB coagulopathy, reducing re-exploration and allogeneic transfusion rates [57]. However, use in this context remains controversial, and its use has been associated with serious thrombotic complications, particularly in the elderly [58].

Patients on DAPT requiring emergency surgery are at high risk of major bleeding and therefore monitoring of platelet function during and after cardiac surgery is crucial. Several point-of-care platelet function testing devices are available, including the Multiplate ${ }^{\circledR}$ (Roche Diagnostics, Rotkreuz, Switzerland), TEG ${ }^{\circledR}$ Platelet Mapping $^{\mathrm{TM}}$ (Haemonetics, Braintree, MA, USA), Rotem ${ }^{\circledR}$ platelet (TEM Int, Munich, Germany), and VerifyNow ${ }^{\circledR}$
(Accriva Diagnostics, San Diego, CA, USA) systems, and have also shown potential use in assessing platelet function in bleeding patients [59].A recent systematic review and meta-analysis found that addition of point-of-care platelet function testing to viscoelastic measurements in transfusion management algorithms resulted a reduction in blood loss and transfusion requirements [60]. However, there is currently a paucity of quality data to support the routine use of point-of-care platelet function testing in predicting bleeding risk in cardiac surgical patients. Despite an increased use of desmopressin (DDAVP) for bleeding related to platelet dysfunction [61], evidence for its efficacy remains limited.

While large-scale studies on thromboprophylaxis are lacking, a recent systematic review did not detect harm from chemical prophylaxis, and recommended commencing therapy at an early stage in the absence of major bleeding [62].

\section{Renal considerations}

The renal medulla is perfused at a low oxygen concentration making the kidneys susceptible to injury because of the limited reserve. AKI occurs in up to $30 \%$ of patients after cardiac surgery and is associated with increased mortality correlated to the severity of AKI [63]. Risk factors independently associated with development of AKI after cardiac surgery include age, hypertension, pre-existing chronic kidney disease, blood transfusion, inotropic support, ECC duration, aortic cross-clamping, restricted oxygen delivery and severe haemodilution [64].

A decrease in renal perfusion and an imbalance between renal oxygen delivery (DO2) and VO2 can lead to significant renal injury. Renal DO2 varies greatly during $\mathrm{CPB}$ and in the postoperative period. Even a shorter period of insufficient $\mathrm{DO} 2$ during $\mathrm{CPB}$ is significantly associated with the occurrence of AKI, while studies suggest that the MAP during CPB has no influence on AKI as long as renal perfusion is adequate [65]. In patients with decompensated heart failure venous congestion, rather than $\mathrm{CO}$, is the important factor in the development of AKI [66].

\section{Recent advances}

Current guidelines for the diagnosis of AKI recommends the use of Kidney Disease Improving Global Outcomes (KDIGO) criteria [67]. An increase in serum creatinine occurs late in the development of AKI and identification of novel biomarkers, such as neutrophil gelatinaseassociated lipocalin and interleukin-18, might in the future help early detection and prognosis in AKI and thereby potentially improving early institution of treatment [68]. Only a few strategies to prevent and manage AKI have been shown to improve outcomes, including 
goal-directed $\mathrm{CPB}$ perfusion maintaining adequate renal DO2 [18], and close attention to intravenous resuscitation and hemodynamic management. Pharmacological means to protect renal function have proven elusive to date.

Strategies to prevent AKI should include identification of patients at risk, treatment of modifiable risk factors and early diagnosis of AKI. A recent meta-analysis in 1479 patients concluded that early (within $12-48 \mathrm{~h}$ of surgery) compared to later initiation of renal replacement therapy reduced mortality at 28 days postoperatively [69].

\section{Neurologic considerations}

The incidence of postoperative (predominantly thromboembolic) ischaemic stroke is up to $4 \%$ for coronary revascularisation and may increase to $10 \%$ for valvular replacements and combined procedures with an additional increase in the setting of perioperative atrial fibrillation [9]. Delirium (often of the hypoactive type) develops in $25-50 \%$ of patients following cardiac surgery and is associated with cognitive decline and increased mortality [70].

Management to minimise the risk or sequelae of neurological complications is mainly supportive and focuses on systolic function and cardiac rhythm, perfusion and oxygenation, fluid, acid-base and electrolyte status to avoid postoperative hypoperfusion. Clinical evidence connects arterial hypotension and ischaemic stroke although this might represent epiphenomena, as the incidence of watershed pattern is variable. Atrial fibrillation is a major cause of perioperative stroke; however, no controlled trials have specifically addressed the use of anticoagulation therapy for new-onset, postoperative atrial fibrillation [71]. Hyperthermia is a risk factor for postoperative cognitive dysfunction and should be avoided, including the period of active rewarming in the intensive care unit following hypothermic CPB. Hyperglycaemia is also associated with adverse neurological outcomes and amenable to intervention in the intensive care unit to maintain normoglycaemia.

\section{Recent advances}

Cerebral oximetry using near-infrared spectroscopy (NIRS) may be helpful to minimise cerebral complications following surgery, particularly during procedures involving the aortic arch. Studies to date have yielded conflicting results and, while desaturation episodes were associated with cerebral complications, there is insufficient evidence to support that NIRS-based algorithms provide clinical benefit [72].

Some studies have utilised NIRS to monitor cerebrovascular autoregulation, based on changes in frontal cerebral tissue oxygen saturation as a surrogate for cerebral blood flow and concurrent arterial pressure changes. The lower limit of autoregulation may be above what is considered a 'safe' MAP, particularly in patients with intra- or extracranial vascular stenoses or chronic hypertension, thus exposing those patients to the risk of cerebral hypoperfusion. The capacity for cerebrovascular autoregulation may vary between individuals and over the perioperative period and highlights the need to tailor MAP accordingly. The degree and cumulative time for MAP excursions below the lower limit of autoregulation have been linked to postoperative adverse neurological and renal events as well as mortality [73] and excursions above the upper limit of autoregulation may be associated with delirium [74].

Few pharmacological therapies have sufficient clinical evidence of efficacy to prevent or treat postoperative cognitive dysfunction and delirium. The use of dexmedetomidine has attracted considerable interest [75], also supported by studies in general ICU populations.

\section{Future research}

Many aspects of critical care management of cardiac surgical patients warrant further clinical investigation (Table 2). Current evidence supporting postoperative ventilation strategies is poor. Postoperative pulmonary dysfunction is multifactorial and closely linked to intraoperative events. Two large RCTs on intra-operative ventilation, recruitment manoeuvres and adherence to lung protective ventilation protocols are ongoing (NCT 03098524 and NCT 03255356).

There is a need for more precise definitions of pulmonary complications in the context of cardiac surgery. The effects of positive end-expiratory pressure and a multimodal approach to potentially more protective ventilation including driving pressure, respiratory rate and flow, also incorporating measures of pulmonary mechanics (ventilator power, strain rate), need investigation. Study protocols should include both intra- and postoperative ventilation. Effects of perioperative hyperoxia, different ventilatory modes including the impact on RV function, and automated weaning protocols represent other areas of investigation.

Large, high-quality RCTs comparing different inotropes are lacking. Notably, monitoring of $\mathrm{CO}$ was not mandatory in several recent large high-quality RCTs on inotropes. While this is a pragmatic approach, more stringent study protocols based on cardiac performance are needed.

Several approaches to the fundamental task of assessing the intravascular volume status merit further evaluation. Mean systemic filling pressure (Pmsf), which is the theoretical pressure in the circulatory system in noflow conditions, reflects the stressed volume. It can be 
Table 2 Areas where further clinical investigation is required

\begin{tabular}{|c|c|}
\hline \multirow[t]{4}{*}{ Ventilation } & $\begin{array}{l}\text { Should lung protective ventilation (e.g. TV } 6 \mathrm{ml} / \mathrm{kg} \text {; PEEP } 10 \mathrm{cmH}_{2} \mathrm{O} \text {; driving pressure }<15 \mathrm{cmH}_{2} \mathrm{O} \text { ) be used postopera- } \\
\text { tively as standard? }\end{array}$ \\
\hline & What is the optimal support following extubation? \\
\hline & Does prophylactic use of high-flow nasal oxygen therapy reduce re-intubation rate? \\
\hline & What is the role of NIV versus high-flow nasal oxygen use in postextubation respiratory failure? \\
\hline \multirow[t]{4}{*}{ Haemodynamics } & What criteria should be used to select patients for invasive vs. non-invasive monitoring of cardiac output? \\
\hline & What are the optimal inotropic/vasoactive agents for supporting cardiac output following cardiac surgery? \\
\hline & What endpoints should be used to titrate fluid therapy? \\
\hline & What is the optimal fluid composition for postoperative cardiac surgical patients? \\
\hline \multirow[t]{2}{*}{ Mechanical circulatory support } & What is the optimal device to support postcardiotomy cardiogenic shock (IABP vs. ECMO vs. Impella vs. other LVADs)? \\
\hline & What is the role and efficacy of temporary RVAD to support RV failure? \\
\hline \multirow[t]{2}{*}{ Echocardiography } & $\begin{array}{l}\text { Are 3D and strain echo assessments helpful to evaluate ventricular performance, guide haemodynamic support and } \\
\text { interventions? }\end{array}$ \\
\hline & $\begin{array}{l}\text { Do miniaturised TOE probes with continuous monitoring offer additional advantages compared to routine intermit- } \\
\text { tent TTE/TOE? }\end{array}$ \\
\hline \multirow[t]{3}{*}{ Haemostasis } & Can point-of-care coagulation testing replace standard laboratory assays? \\
\hline & What criteria should be used to define the trigger for red cell transfusion? \\
\hline & What is the role factor concentrates in managing postoperative bleeding? \\
\hline Acute kidney injury & What strategy for early detection and management of AKI should be used? \\
\hline Neurology & What neuromonitoring should be used to prevent adverse neurological outcomes? \\
\hline
\end{tabular}

estimated at the patient's bedside from the relationship between $\mathrm{CO}$ and right atrial pressure during inspiratory pause procedures [76], or using mathematical models after measurement of $\mathrm{CO}$, right atrial pressure and MAP [77]. Furthermore, Pmsf allows the calculation of systemic vascular compliance, which may help guiding vasopressor therapy [78]. Although theoretically appealing, very little evidence exists about the clinical impact of Pmsf in the management of postoperative patients.

The adaptation of arterial elastance to end-systolic ventricular elastance (ventriculo-arterial coupling) may be used to optimise the efficiency of cardiac workload, with important potential implications in the management of the failing heart [79].

Recently, the importance of circadian rhythm to tolerate the ischaemia-reperfusion associated with $\mathrm{CPB}$ has been highlighted, and a molecular mechanism was suggested [80]. Further research into the mechanism of ischaemia-reperfusion tolerance as well as logistics of scheduling patients to morning or afternoon operation lists seems warranted.

While multimodal brain monitoring and neuroprotective interventions have been studied intra-operatively, there is a paucity of similar studies in the perioperative and immediate postoperative period. The relatively unchanged incidence of adverse neurological events following cardiac surgery in part reflects an incomplete understanding of the pathophysiology beyond cerebral perfusion pressure and blood flow. The association between neurological deficits and altered neurotransmission, inflammation, blood-brain barrier impairment, microglial activation, neuroendocrine responses and genetic factors are important areas of ongoing and future clinical research.

Minimally invasive surgery is an increasingly common approach to aortic and mitral valve surgery, mostly using a right mini-thoracotomy. It is also feasible for revascularisation procedures, even multiple, using a left anterolateral route [8]. Apart from their cosmetic advantages, such approaches may decrease surgical insults, reducing postoperative pain and duration of mechanical ventilation. However, questions persist about their safety, some reporting prolonged duration of $\mathrm{CPB}$ and aortic cross-clamp time, higher rates of bleeding, pulmonary complications and phrenic nerve injury [8] and a higher risk of stroke using retrograde femoral cannulation [81]. Although several cohort studies described the feasibility of minimally invasive approaches, randomised data are to date restricted to 10 small trials, 7 during aortic and 3 during mitral valve procedures. Although perioperative mortality was not affected, minimally invasive surgery was associated with a trend towards fewer transfusions, less pain, and faster mobilisation [8]. Further larger trials are needed to evaluate these technically demanding approaches.

Finally, it should be emphasised how crucial networks are in organising this future research, to facilitate larger studies and create consensus for standards of care. Among existing networks, ELSO (www.elso.org) and ECMOnet (www.internationalecmonetwork.org) may 
have a particular role in orchestrating the big effort of research remaining in the management of ECMO, in particular, in the postcardiac surgery setting.

\begin{abstract}
Author details
${ }^{1}$ Intensive Care Unit, Liverpool Hospital, Southwestern Sydney Local Health District, Locked Bag 7103, Liverpool BC, NSW 1871, Australia. ${ }^{2}$ Medical-Surgical Intensive Care Unit, Hôpital Pitié-Salpêtrière, Assistance Publique-Hôpitaux de Paris, Paris, France. ${ }^{3}$ Department of Medicine, Columbia University College of Physicians and Surgeons, New York-Presbyterian Hospital, New York, NY, USA. ${ }^{4}$ Department of Critical Care Medicine, Mater Misericordiae University Hospital, Dublin, Ireland. ${ }^{5}$ Adult Intensive Care Service, The Prince Charles Hospital, Brisbane, Australia. ${ }^{6}$ Department of Anaesthesia \& Intensive Care, Prince of Wales Hospital, The Chinese University of Hong Kong, Shatin, New Territories, Hong Kong. ${ }^{7}$ Intensive Care Unit, Liverpool Hospital, Southwestern Sydney Local Health District, Sydney, Australia. ${ }^{8}$ Department of Cardiothoracic Anesthesiology, Rigshospitalet, University of Copenhagen, Copenhagen, Denmark. ${ }^{9}$ Department of Intensive Care Medicine, Inselspital, Bern University Hospital, University of Bern, Bern, Switzerland. ${ }^{10}$ Department of Anaesthesia, Papworth Hospital, Cambridge, UK. ${ }^{11}$ Cardiothoracic Surgical Unit, Royal Prince Alfred Hospital, The University of Sydney, Sydney, Australia.
\end{abstract}

\section{Compliance with ethical standards}

\section{Conflicts of interest}

Drs Anders Aneman, Peter McCanny, Frances Colreavy, Peter Hasse MollerSorensen do not have any relevant conflicts of interest to declare. Dr Brodie is currently the co-chair of the Trial Steering Committee for the VENT-AVOID trial sponsored by ALung Technologies and Kadence (Johnson \& Johnson). All compensation for these activities is paid to Columbia University. Dr Vallely is a proctor for Abbott and serves on an Advisory Board for Medtronic.

Received: 20 February 2018 Accepted: 12 April 2018

Published online: 30 April 2018

\section{References}

1. Friedrich I, Simm A, Kotting J, Tholen F, Fischer B, Silber RE (2009) Cardiac surgery in the elderly patient. Dtsch Arzteblatt Int 106:416-422

2. Downs E, Lim S, Ragosta M, Yount K, Yarboro L, Ghanta R, Kern J, Kron I, Ailawadi G (2015) The influence of a percutaneous mitral repair program on surgical mitral valve volume. J Thorac Cardiovasc Surg 150:1093-1097

3. Mack MJ (2013) Predicting risk in procedures for aortic stenosis: the next step forward. Eur J Cardio Thorac Surg 43:883-885

4. Vallely MP, Wilson MK, Adams M, Ng MK (2012) How to set up a successful TAVI program. Ann Cardiothorac Surg 1:185-189

5. Dhurandhar V, Saxena A, Parikh R, Vallely MP, Wilson MK, Butcher JK, Black DA, Tran L, Reid CM, Bannon PG (2015) Comparison of the safety and efficacy of on-pump (ONCAB) versus off-pump (OPCAB) coronary artery bypass graft surgery in the elderly: a review of the ANZSCTS database. Heart Lung Circ 24:1225-1232

6. Zhao DF, Edelman JJ, Seco M, Bannon PG, Wilson MK, Byrom MJ, Thourani V, Lamy A, Taggart DP, Puskas JD, Vallely MP (2017) Coronary artery bypass grafting with and without manipulation of the ascending aorta: a network meta-analysis. J Am Coll Cardiol 69:924-936

7. Seco M, Martinez GJ, Edelman JJ, Ng HK, Vallely MP, Wilson MK, Ng MK (2015) Combined total-arterial, off-pump coronary artery bypass grafting and transaortic transcatheter aortic valve implantation. Int J Cardiol 201:587-589

8. Doenst T, Diab M, Sponholz C, Bauer M, Farber G (2017) The opportunities and limitations of minimally invasive cardiac surgery. Dtsch Arzteblatt Int 114:777-784

9. Nearman H, Klick JC, Eisenberg P, Pesa N (2014) Perioperative complications of cardiac surgery and postoperative care. Crit Care Clin 30:527-555

10. Zochios V, Klein AA, Gao F, (2017) Protective invasive ventilation in cardiac surgery: a systematic review with a focus on acute lung injury in adult cardiac surgical patients. J Cardiothorac Vasc Anesth. https://doi. org/10.1053/j.jcva.2017.10.031

11. Zhu F, Gomersall CD, Ng SK, Underwood MJ, Lee A (2015) A randomized controlled trial of adaptive support ventilation mode to wean patients after fast-track cardiac valvular surgery. Anesthesiology 122:832-840

12. Parke R, McGuinness S, Dixon R, Jull A (2013) Open-label, phase II study of routine high-flow nasal oxygen therapy in cardiac surgical patients. Br J Anaesth 111:925-931

13. Stephan F, Barrucand B, Petit P, Rezaiguia-Delclaux S, Medard A, Delannoy B, Cosserant B, Flicoteaux G, Imbert A, Pilorge C, Berard L (2015) High-flow nasal oxygen vs noninvasive positive airway pressure in hypoxemic patients after cardiothoracic surgery: a randomized clinical trial. JAMA 313:2331-2339

14. Jakob SM, Ruokonen E, Takala J (2000) Assessment of the adequacy of systemic and regional perfusion after cardiac surgery. Br J Anaesth 84:571-577

15. Lannemyr L, Bragadottir G, Krumbholz V, Redfors B, Sellgren J, Ricksten SE (2017) Effects of cardiopulmonary bypass on renal perfusion, filtration, and oxygenation in patients undergoing cardiac surgery. Anesthesiology 126:205-213

16. Holm J, Hakanson E, Vanky F, Svedjeholm R (2011) Mixed venous oxygen saturation predicts short- and long-term outcome after coronary artery bypass grafting surgery: a retrospective cohort analysis. Br J Anaesth 107:344-350

17. Majure DT, Greco T, Greco M, Ponschab M, Biondi-Zoccai G, Zangrillo A, Landoni $G$ (2013) Meta-analysis of randomized trials of effect of milrinone on mortality in cardiac surgery: an update. J Cardiothorac Vasc Anesth 27:220-229

18. Li P, Qu LP, Qi D, Shen B, Wang YM, Xu JR, Jiang WH, Zhang H, Ding XQ, Teng $J$ (2017) Significance of perioperative goal-directed hemodynamic approach in preventing postoperative complications in patients after cardiac surgery: a meta-analysis and systematic review. Ann Med 49:343-351

19. Bignami E, Guarnieri M, Gemma M (2017) Fluid management in cardiac surgery patients: pitfalls, challenges and solutions. Minerva Anestesiol 83:638-651

20. Mehta RH, Leimberger JD, van Diepen $S$, Meza J, Wang A, Jankowich R, Harrison RW, Hay D, Fremes S, Duncan A, Soltesz EG, Luber J, Park S, Argenziano M, Murphy E, Marcel R, Kalavrouziotis D, Nagpal D, Bozinovski J, Toller W, Heringlake M, Goodman SG, Levy JH, Harrington RA, Anstrom KJ, Alexander JH, Investigators L-C (2017) Levosimendan in patients with left ventricular dysfunction undergoing cardiac surgery. N Engl J Med 376:2032-2042

21. Cholley B, Caruba T, Grosjean S, Amour J, Ouattara A, Villacorta J, Miguet B, Guinet P, Levy F, Squara P, Ait Hamou N, Carillion A, Boyer J, Boughenou MF, Rosier S, Robin E, Radutoiu M, Durand M, Guidon C, Desebbe O, Charles-Nelson A, Menasche P, Rozec B, Girard C, Fellahi JL, Pirracchio R, Chatellier G (2017) Effect of levosimendan on low cardiac output syndrome in patients with low ejection fraction undergoing coronary artery bypass grafting with cardiopulmonary bypass: the LICORN randomized clinical trial. JAMA 318:548-556

22. Landoni G, Lomivorotov VV, Alvaro G, Lobreglio R, Pisano A, Guarracino F, Calabro MG, Grigoryev EV, Likhvantsev WV, Salgado-Filho MF, Bianchi A, Pasyuga W, Baiocchi M, Pappalardo F, Monaco F, Boboshko VA, Abubakirov MN, Amantea B, Lembo R, Brazzi L, Verniero L, Bertini P, Scandroglio AM, Bove T, Belletti A, Michienzi MG, Shukevich DL, Zabelina TS, Bellomo R, Zangrillo A (2017) Levosimendan for hemodynamic support after cardiac surgery. N Engl J Med 376:2021-2031

23. Putzu A, Clivio S, Belletti A, Cassina T (2018) Perioperative levosimendan in cardiac surgery: a systematic review with meta-analysis and trial sequential analysis. Int J Cardiol 251:22-31

24. Landoni G, Pasin L, Di Prima AL, Dossi R, Taddeo D, Zangrillo A (2014) Methylene blue: between scylla (meta-analysis) and charybdis (propensity). J Cardiothorac Vasc Anesth 28:e12-e13

25. Benstoem C, Stoppe C, Liakopoulos OJ, Ney J, Hasenclever D, Meybohm P, Goetzenich A (2017) Remote ischaemic preconditioning for coronary artery bypass grafting (with or without valve surgery). Cochrane Database Syst Rev 5:CD011719

26. van Diepen S, Katz JN, Albert NM, Henry TD, Jacobs AK, Kapur NK, Kilic A, Menon V, Ohman EM, Sweitzer NK, Thiele H, Washam JB, Cohen MG, American Heart Association Council on Clinical C, Council on C, Stroke 
N, Council on Quality of C, Outcomes R, Mission L (2017) Contemporary management of cardiogenic shock: a scientific statement from the American Heart Association. Circulation 136:e232-e268

27. Schmidt M, Burrell A, Roberts L, Bailey M, Sheldrake J, Rycus PT, Hodgson C, Scheinkestel C, Cooper DJ, Thiagarajan RR, Brodie D, Pellegrino V, Pilcher D (2015) Predicting survival after ECMO for refractory cardiogenic shock: the survival after veno-arterial-ECMO (SAVE)-score. Eur Heart J 36:2246-2256

28. Thiele H, Zeymer U, Neumann FJ, Ferenc M, Olbrich HG, Hausleiter J, Richardt G, Hennersdorf M, Empen K, Fuernau G, Desch S, Eitel I, Hambrecht R, Fuhrmann J, Bohm M, Ebelt H, Schneider S, Schuler G, Werdan K (2012) Intraaortic balloon support for myocardial infarction with cardiogenic shock. N Engl J Med 367:1287-1296

29. Miller PE, Solomon MA, McAreavey D (2017) Advanced percutaneous mechanical circulatory support devices for cardiogenic shock. Crit Care Med 45:1922-1929

30. Rihal CS, Naidu SS, Givertz MM, Szeto WY, Burke JA, Kapur NK, Kern M, Garratt KN, Goldstein JA, Dimas V, Tu T (2015) 2015 SCAl/ACC/HFSA/ STS clinical expert consensus statement on the use of percutaneous mechanical circulatory support devices in cardiovascular care: endorsed by the American Heart Association, the Cardiological Society of India, and Sociedad Latino Americana de Cardiologia Intervencionista; Affirmation of Value by the Canadian Association of Interventional CardiologyAssociation Canadienne de Cardiologie d'intervention. J Am Coll Cardiol 65:2140-2141

31. Abrams D, Combes A, Brodie D (2014) Extracorporeal membrane oxygenation in cardiopulmonary disease in adults. J Am Coll Cardiol 63:2769-2778

32. Rosenzweig EB, Brodie D, Abrams DC, Agerstrand CL, Bacchetta M (2014) Extracorporeal membrane oxygenation as a novel bridging strategy for acute right heart failure in group 1 pulmonary arterial hypertension (American Society for Artificial Internal Organs: 1992). ASAIO J 60:129-133

33. Paden ML, Conrad SA, Rycus PT, Thiagarajan RR (2013) Extracorporeal life support organization registry report 2012 (American Society for Artificial Internal Organs: 1992). ASAIO J 59:202-210

34. Karagiannidis C, Brodie D, Strassmann S, Stoelben E, Philipp A, Bein T, Muller T, Windisch W (2016) Extracorporeal membrane oxygenation: evolving epidemiology and mortality. Intensive Care Med 42:889-896

35. Ponikowski P, Voors AA, Anker SD, Bueno H, Cleland JG, Coats AJ, Falk V, Gonzalez-Juanatey JR, Harjola VP, Jankowska EA, Jessup M, Linde C, Nihoyannopoulos P, Parissis JT, Pieske B, Riley JP, Rosano GM, Ruilope LM, Ruschitzka F, Rutten FH, van der Meer P (2016) 2016 ESC Guidelines for the diagnosis and treatment of acute and chronic heart failure: the Task Force for the diagnosis and treatment of acute and chronic heart failure of the European Society of Cardiology (ESC). Developed with the special contribution of the Heart Failure Association (HFA) of the ESC. Eur J Heart Fail 18:891-975

36. Anderson M, Morris L, Tang D, Batsides G, Kirtane A, Hanson I, Meraj P, Kapur N, O'Neill W (2017) Impella RP post approval study: first multicenter, prospective post market approval results for the impella RP in patients with right ventricular failure. J Heart Lung Transplant 36:S64-S65

37. Schmack B, Weymann A, Popov AF, Patil NP, Sabashnikov A, Kremer J, Farag M, Brcic A, Lichtenstern C, Karck M, Ruhparwar A (2016) Concurrent Left ventricular assist device (LVAD) implantation and percutaneous temporary RVAD support via cardiacassist protek-duo tandemheart to preempt right heart failure. Med Sci Monit Basic Res 22:53-57

38. Canty DJ, Heiberg J, Tan JA, Yang Y, Royse AG, Royse CF, Mobeirek A, Shaer FE, Albacker T, Nazer Rl, Fouda M, Bakir BM, Alsaddique AA (2017) Assessment of image quality of repeated limited transthoracic echocardiography after cardiac surgery. J Cardiothorac Vasc Anesth 31:965-972

39. Fletcher N, Geisen M, Meeran H, Spray D, Cecconi M (2015) Initial clinical experience with a miniaturized transesophageal echocardiography probe in a cardiac intensive care unit. J Cardiothorac Vasc Anesth 29:582-587

40. Cavarocchi NC, Pitcher HT, Yang Q, Karbowski P, Miessau J, Hastings HM, Hirose H (2013) Weaning of extracorporeal membrane oxygenation using continuous hemodynamic transesophageal echocardiography. J Thorac Cardiovasc Surg 146:1474-1479

41. Kumar A, Puri GD, Bahl A (2017) Transesophageal echocardiography, 3-dimensional and speckle tracking together as sensitive markers for early outcome in patients with left ventricular dysfunction undergoing cardiac surgery. J Cardiothorac Vasc Anesth 31:1695-1701

42. Cinotti R, Delater A, Fortuit C, Roquilly A, Mahe PJ, Demeure-dit-Latte D, Asehnoune K (2015) Speckle-tracking analysis of left ventricular systolic function in the intensive care unit. Anaesthesiol intensive Ther 47:482-486

43. Kato TS, Jiang J, Schulze PC, Jorde U, Uriel N, Kitada S, Takayama H, Naka Y, Mancini D, Gillam L, Homma S, Farr M (2013) Serial echocardiography using tissue Doppler and speckle tracking imaging to monitor right ventricular failure before and after left ventricular assist device surgery. JACC Heart Fail 1:216-222

44. Kinnunen EM, De Feo M, Reichart D, Tauriainen T, Gatti G, Onorati F, Maschietto L, Bancone C, Fiorentino F, Chocron S, Bounader K, Dalen M, Svenarud P, Faggian G, Franzese I, Santarpino G, Fischlein T, Maselli D, Dominici C, Nardella S, Gherli R, Musumeci F, Rubino AS, Mignosa C, Mariscalco G, Serraino FG, Santini F, Salsano A, Nicolini F, Gherli T, Zanobini M, Saccocci M, Ruggieri VG, Philippe Verhoye J, Perrotti A, Biancari F (2017) Incidence and prognostic impact of bleeding and transfusion after coronary surgery in low-risk patients. Transfusion 57:178-186

45. Thiele RH, Raphael J (2014) A 2014 update on coagulation management for cardiopulmonary bypass. Semin Cardiothorac Vasc Anesth 18:177-189

46. Fominskiy E, Nepomniashchikh VA, Lomivorotov VV, Monaco F, Vitiello C, Zangrillo A, Landoni G (2016) Efficacy and safety of fibrinogen concentrate in surgical patients: a meta-analysis of randomized controlled trials. J Cardiothorac Vasc Anesth 30:1196-1204

47. Myles PS, Smith JA, Forbes A, Silbert B, Jayarajah M, Painter T, Cooper DJ, Marasco S, McNeil J, Bussieres JS, Wallace S (2016) Stopping vs. continuing aspirin before coronary artery surgery. N Engl J Med 374:728-737

48. Mazzeffi MA, Lee K, Taylor B, Tanaka KA (2017) Perioperative management and monitoring of antiplatelet agents: a focused review on aspirin and P2Y12 inhibitors. Korean J Anesthesiol 70:379-389

49. Task Force M, Windecker S, Kolh P, Alfonso F, Collet JP, Cremer J, Falk V, Filippatos G, Hamm C, Head SJ, Juni P, Kappetein AP, Kastrati A, Knuuti J, Landmesser U, Laufer G, Neumann FJ, Richter DJ, Schauerte P, Sousa Uva M, Stefanini GG, Taggart DP, Torracca L, Valgimigli M, Wijns W, Witkowski A (2014) 2014 ESC/EACTS Guidelines on myocardial revascularization: the task force on myocardial revascularization of the European Society of Cardiology (ESC) and the European Association for Cardio-Thoracic Surgery (EACTS) developed with the special contribution of the European Association of Percutaneous Cardiovascular Interventions (EAPCI). Eur Heart J 35:2541-2619

50. Kilic A, Whitman GJ (2014) Blood transfusions in cardiac surgery: indications, risks, and conservation strategies. Ann Thorac Surg 97:726-734

51. Hajjar LA, Vincent JL, Galas FR, Nakamura RE, Silva CM, Santos MH, Fukushima J, Kalil Filho R, Sierra DB, Lopes NH, Mauad T, Roquim AC, Sundin MR, Leao WC, Almeida JP, Pomerantzeff PM, Dallan LO, Jatene FB, Stolf NA, Auler JO Jr (2010) Transfusion requirements after cardiac surgery: the TRACS randomized controlled trial. JAMA 304:1559-1567

52. Murphy GJ, Pike K, Rogers CA, Wordsworth S, Stokes EA, Angelini GD, Reeves BC (2015) Liberal or restrictive transfusion after cardiac surgery. N Engl J Med 372:997-1008

53. Mazer CD, Whitlock RP, Fergusson DA, Hall J, Belley-Cote E, Connolly K, Khanykin B, Gregory AJ, de Medicis E, McGuinness S, Royse A, Carrier FM, Young PJ, Villar JC, Grocott HP, Seeberger MD, Fremes S, Lellouche F, Syed S, Byrne K, Bagshaw SM, Hwang NC, Mehta C, Painter TW, Royse C, Verma S, Hare GMT, Cohen A, Thorpe KE, Juni P, Shehata N (2017) Restrictive or liberal red-cell transfusion for cardiac surgery. N Engl J Med 377:2133-2144

54. Cooper DJ, McQuilten ZK, Nichol A, Ady B, Aubron C, Bailey M, Bellomo R, Gantner D, Irving DO, Kaukonen KM, McArthur C, Murray L, Pettila V, French C (2017) Age of red cells for transfusion and outcomes in critically ill adults. N Engl I Med 377:1858-1867

55. Heddle NM, Cook RJ, Arnold DM, Liu Y, Barty R, Crowther MA, Devereaux PJ, Hirsh J, Warkentin TE, Webert KE, Roxby D, Sobieraj-Teague M, Kurz A Sessler DI, Figueroa P, Ellis M, Eikelboom JW (2016) Effect of short-term vs. long-term blood storage on mortality after transfusion. N Engl J Med 375:1937-1945

56. Cappabianca G, Mariscalco G, Biancari F, Maselli D, Papesso F, Cottini M, Crosta S, Banescu S, Ahmed AB, Beghi C (2016) Safety and efficacy of prothrombin complex concentrate as first-line treatment in bleeding after cardiac surgery. Critical Care (Lond, Engl) 20:5 
57. Gill R, Herbertson M, Vuylsteke A, Olsen PS, von Heymann C, Mythen M, Sellke F, Booth F, Schmidt TA (2009) Safety and efficacy of recombinant activated factor VIl: a randomized placebo-controlled trial in the setting of bleeding after cardiac surgery. Circulation 120:21-27

58. Levi M, Levy JH, Andersen HF, Truloff D (2010) Safety of recombinant activated factor VII in randomized clinical trials. N Engl J Med 363:1791-1800

59. Koltai K, Kesmarky G, Feher G, Tibold A, Toth K (2017) Platelet aggregometry testing: molecular mechanisms, techniques and clinical implications. Int J Mol Sci 18:1803. https://doi.org/10.3390/ijms18081803

60. Corredor C, Wasowicz M, Karkouti K, Sharma V (2015) The role of pointof-care platelet function testing in predicting postoperative bleeding following cardiac surgery: a systematic review and meta-analysis. Anaesthesia 70:715-731

61. Orlov D, McCluskey SA, Callum J, Rao V, Moreno J, Karkouti K (2017) Utilization and effectiveness of desmopressin acetate after cardiac surgery supplemented with point-of-care hemostatic testing: a propensity-scorematched analysis. J Cardiothorac Vasc Anesth 31:883-895

62. Ho KM, Bham E, Pavey W (2015) Incidence of venous thromboembolism and benefits and risks of thromboprophylaxis after cardiac surgery: a systematic review and meta-analysis. J Am Heart Assoc 4:e002652

63. Hobson CE, Yavas S, Segal MS, Schold JD, Tribble CG, Layon AJ, Bihorac A (2009) Acute kidney injury is associated with increased long-term mortality after cardiothoracic surgery. Circulation 119:2444-2453

64. Wang Y, Bellomo R (2017) Cardiac surgery-associated acute kidney injury: risk factors, pathophysiology and treatment. Nat Rev Nephrol 13:697-711

65. Kandler K, Jensen ME, Nilsson JC, Moller CH, Steinbruchel DA (2015) Arterial pressure during cardiopulmonary bypass is not associated with acute kidney injury. Acta Anaesthesiol Scand 59:625-631

66. Gambardella I, Gaudino M, Ronco C, Lau C, Ivascu N, Girardi LN (2016) Congestive kidney failure in cardiac surgery: the relationship between central venous pressure and acute kidney injury. Interactive Cardiovasc Thorac Surg 23:800-805

67. Khwaja A (2012) KDIGO clinical practice guidelines for acute kidney injury Nephron Clin Pract 120:c179-c184

68. Parikh CR, Puthumana J, Shlipak MG, Koyner JL, Thiessen-Philbrook H, McArthur E, Kerr K, Kavsak P, Whitlock RP, Garg AX, Coca SG (2017) Relationship of kidney injury biomarkers with long-term cardiovascular outcomes after cardiac surgery. J Am Soc Nephrol 28:3699-3707

69. Zou H, Hong Q, Xu G (2017) Early versus late initiation of renal replacement therapy impacts mortality in patients with acute kidney injury post cardiac surgery: a meta-analysis. Critical Care (Lond, Engl) 21:150

70. Brown CH (2014) Delirium in the cardiac surgical ICU. Curr Opin Anaesthesiol 27:117-122
71. Megens MR, Churilov L, Thijs V, (2017) New-onset atrial fibrillation after coronary artery bypass graft and long-term risk of stroke: a meta-analysis. J Am Heart Assoc 6. https://doi.org/10.1161/JAHA.117.007558

72. Serraino GF, Murphy GJ (2017) Effects of cerebral near-infrared spectroscopy on the outcome of patients undergoing cardiac surgery: a systematic review of randomised trials. BMJ Open 7:e016613

73. Ono M, Brady K, Easley RB, Brown C, Kraut M, Gottesman RF, Hogue CW Jr (2014) Duration and magnitude of blood pressure below cerebral autoregulation threshold during cardiopulmonary bypass is associated with major morbidity and operative mortality. J Thorac Cardiovasc Surg 147:483-489

74. Hori D, Brown C, Ono M, Rappold T, Sieber F, Gottschalk A, Neufeld KJ, Gottesman R, Adachi H, Hogue CW (2014) Arterial pressure above the upper cerebral autoregulation limit during cardiopulmonary bypass is associated with postoperative delirium. Br J Anaesth 113:1009-1017

75. Liu X, Xie G, Zhang K, Song S, Song F, Jin Y, Fang X (2017) Dexmedetomidine vs propofol sedation reduces delirium in patients after cardiac surgery: a meta-analysis with trial sequential analysis of randomized controlled trials. J Crit Care 38:190-196

76. Maas JJ, Geerts BF, van den Berg PC, Pinsky MR, Jansen JR (2009) Assessment of venous return curve and mean systemic filling pressure in postoperative cardiac surgery patients. Crit Care Med 37:912-918

77. Gupta K, Sondergaard S, Parkin G, Leaning M, Aneman A (2015) Applying mean systemic filling pressure to assess the response to fluid boluses in cardiac post-surgical patients. Intensive Care Med 41:265-272

78. Maas JJ, Pinsky MR, Aarts LP, Jansen JR (2012) Bedside assessment of total systemic vascular compliance, stressed volume, and cardiac function curves in intensive care unit patients. Anesth Analg 115:880-887

79. Guinot PG, Longrois D, Kamel S, Lorne E, Dupont H (2018) Ventriculoarterial coupling analysis predicts the hemodynamic response to norepinephrine in hypotensive postoperative patients: a prospective observational study. Crit Care Med 46:e17-e25

80. Montaigne D, Marechal X, Modine T, Coisne A, Mouton S, Fayad G, Ninni S, Klein C, Ortmans S, Seunes C, Potelle C, Berthier A, Gheeraert C, Piveteau C, Deprez R, Eeckhoute J, Duez H, Lacroix D, Deprez B, Jegou B, Koussa M, Edme JL, Lefebvre P, Staels B (2018) Daytime variation of perioperative myocardial injury in cardiac surgery and its prevention by Rev-Erbalpha antagonism: a single-centre propensity-matched cohort study and a randomised study. Lancet 391:59-69

81. Modi P, Chitwood WR Jr (2013) Retrograde femoral arterial perfusion and stroke risk during minimally invasive mitral valve surgery: is there cause for concern? Ann Cardiothorac Surg 2:E1 